\title{
Postoperative Mastoid Aeration Following Canal Wall Up Mastoidectomy according to Preoperative Middle Ear Disease: Analysis of Temporal Bone Computed Tomography Scans
}

\author{
Oh Joon Kwon, Jae Moon Sung, Hwi Kyeong Jung, and Chang Woo Kim \\ Department of Otorhinolaryngology-Head \& Neck Surgery, Hallym University College of Medicine, Seoul, Korea
}

\author{
Received April 25, 2017 \\ Revised June 29,2017 \\ Accepted July 13, 2017

Address for correspondence
Chang Woo Kim, MD
Department of Otorhinolaryngology-
Head \& Neck Surgery,
Hallym University
College of Medicine,
150 Seongan-ro, Gangdong-gu,
Seoul 05355, Korea
Tel +82-2-2224-2279
Fax+82-2-482-2279
E-mail kcw5088@dreamwiz.com

Background and Objectives: The aim of our study was to evaluate postoperative mastoid aeration according to the preoperative middle ear disease and investigate the factors affecting it. Subjects and Methods: We retrospectively reviewed the high-resolution computed tomography (CT) scans of temporal bones that were taken 1 year after surgery. The postoperative mastoid aeration was evaluated according to the preoperative diagnosis, and classified into three groups: grade 1 (complete mastoid aeration), an air-filled epitympanum and mastoid cavity; grade 2 (partial mastoid aeration), an air-filled epitympanum and partially aerated mastoid cavity; and grade 3 (absence of mastoid aeration), no air space in the mastoid cavity. Results: The overall mastoid aeration rate was $55.8 \%$, with adhesive otitis media accounting for $21.2 \%$, attic cholesteatoma $53.8 \%$, and chronic otitis media $75.4 \%$. The rates of postoperative mastoid aeration were significantly higher in the chronic otitis media cases and attic cholesteatoma cases than in the adhesive otitis media cases. There were 14 cases requiring revision operations due to the development of a retraction pocket in the tympanic membrane. All of the revised cases had grade 3 postoperative mastoid aeration, and underwent canal wall down mastoidectomies. Conclusions: The degree of postoperative mastoid aeration is associated with the preoperative middle ear disease. When planning a canal wall up mastoidectomy, the surgeon should contemplate the middle ear disease, because a canal wall down mastoidectomy or mastoid obliteration is recommended if the patient has adhesive otitis media.

J Audiol Otol 2017;21(3):140-145

KEY WORDS: Computed tomography · Cholesteatoma · Otitis media Otologic surgical procedure.

\section{Introduction}

A mastoidectomy is a widely used surgical procedure, usually performed with a tympanoplasty, to eradicate disease in the middle ear cavity and mastoid [1]. It is considered to be an effective method of treatment in cases of chronic ear infections resistant to antibiotic therapy [2]. The use of a mastoidectomy as a means to establish drainage of a complicated infection of the ear has little controversy [3]; however, the use

This is an Open Access article distributed under the terms of the Creative Commons Attribution Non-Commercial License (http://creativecommons.org/licenses/by-nc/4.0/) which permits unrestricted non-commercial use, distribution, and reproduction in any medium, provided the original work is properly cited. of a mastoidectomy to treat chronic drainage or suppuration from otitis media remains an issue of debate [4]. The rationale for a mastoidectomy combined with a tympanoplasty is that it can allow the surgical debridement of infected and devitalized tissues that can lead to persistent middle ear disease [5], as well as reconstruction of the aerated mastoid cavity. The mastoid air cell system acts primarily as a buffer to pressure changes in the middle ear [6], and the presence of an aerated mastoid greatly increases the volume of the middle ear system, which can moderate pressure changes in the middle ear cavity. Thus, in a well-aerated mastoid, significant changes in the middle ear pressure will likely have little effect on the middle ear and tympanic membrane [6]. Therefore, if surgery could increase the air volume in a poorly aerated mastoid cav- 
ity, the sequelae of chronic negative pressure, including atelectasis and cholesteatoma, could be reduced [7].

Unfortunately, the re-aeration of the mastoid cavity after a canal wall up mastoidectomy is not universally achieved. For example, Vrabec, et al. [7] reported that only $46 \%$ of 35 patients with prior unilateral canal wall up mastoidectomies showed good mastoid aeration. They concluded from a review of several previous reports that the prevalence of mastoid aeration following a canal wall up mastoidectomy was no greater than $50 \%$.

In this study, we aimed to evaluate the postoperative mastoid aeration, according to the preoperative middle ear disease, and investigate those factors affecting it. We believe that this study will provide background knowledge to predict postoperative mastoid aeration, and help to determine the method of mastoid management.

\section{Subjects and Methods}

For this research, we conducted a retrospective study of consecutive high-resolution computed tomography (CT) scans of the temporal bones which were taken 1 year after surgery, between March 2008 and December 2012 in a tertiary-care referral center. The study group was comprised of those patients who underwent canal wall up mastoidectomies with tympanoplasties for chronic ear disease. The tympanic membrane was reconstructed with the temporalis muscle fascia after the eradication of the middle ear disease. The preoperative diagnoses were classified as chronic suppurative otitis media, adhesive otitis media, or attic cholesteatoma according to the main clinical expressions and histopathological characteristics. Those patients with chronic suppurative otitis media had consistent or intermittent otorrhea that lasted for more than 3 months. Adhesive otitis media was diagnosed when the tympanic membrane was adherent to the promontory, and the mucosal surfaces were not present [8]. A thin silastic sheet (BioPlexus, Ventura, CA, USA) was inserted into the middle ear cavity when the middle ear mucosa was removed.

There were no cases of pars tensa cholesteatoma in this study because these patients underwent canal wall down mastoidectomies due to aggressive involvement. Those patients with revision operations or temporal bone fractures were ex- cluded from this research because of the possibility of distortion of the normal anatomy. In addition, those patients with extensive attic cholesteatoma in which the size of the attic defect was greater than $0.3 \times 0.3 \mathrm{~cm}$ or cholesteatoma beyond the epitympanum were excluded. The attic defects were reconstructed using the tragal cartilage and perichondrium [9]. Any of the patients who had postoperative perforations of the tympanic membrane or tympanostomy tube insertion combined with the initial operation were excluded to provide an adequate evaluation. Moreover, those patients under the age of 15 years old were excluded because of the possibility of the underdevelopment of mastoid pneumatization. Each of the patients of this study underwent a posterior tympanotomy to create a ventilation route to the mastoid antrum.

We evaluated the postoperative mastoid aeration according to the preoperative diagnosis, preservation of the attic mucosa, and patency of the pathway through the posterior tympanotomy, as well as any complications, including the development of recurrent cholesteatomas, and the status of the tympanic membrane graft. The temporal bone CT was obtained using the following parameters; $140 \mathrm{kV}, 250 \mathrm{mAs}$, and a $0.75 \mathrm{~mm}$ section (MX 8,000 IDT; Philips, Amsterdam, Netherlands). The aeration in the mastoid cavity was determined via CT scans using the horizontal and coronal views in which the cochlea could be seen most clearly. The postoperative mastoid aeration was classified into three groups based on the grading system of Minoda, et al. [10] (Table 1, Fig. 1): grade 1 (complete mastoid aeration), an air-filled epitympanum and mastoid cavity; grade 2 (partial mastoid aeration), an air-filled epitympanum and partially aerated mastoid cavity; and grade 3 (absence of mastoid aeration), no air space in the mastoid cavity. Two independent observers (OJK, CWK) who had no clinical information for the preoperative diagnosis determined the degree of the postoperative mastoid aeration. When there were discrepant results, the lower grades were selected. The audiometric analysis was performed using the average of the hearing threshold at $0.5,1,2$, and $3 \mathrm{kHz}$ preoperatively, and 12 months after the operation. Postoperative mastoid aeration according to the preoperative diagnosis was analyzed by means of Fisher's exact test for the pairwise comparisons between diagnoses; a $p$-value of 0.017 was considered to indicate statistical significance (accounting for a Bonferroni correction). Con-

Table 1. Grade of postoperative mastoid aeration with a modification of the grading system of Minoda, et al.

\begin{tabular}{ll}
\hline \multicolumn{1}{c}{ Grade } & \multicolumn{1}{c}{ Characteristics } \\
\hline 1. Complete mastoid aeration & An air-filled epitympanum and mastoid cavity \\
2. Partial mastoid aeration & An air-filled epitympanum and partially aerated mastoid cavity \\
3. Absence of mastoid aeration & No air space in the mastoid cavity \\
\hline Adapted from Minoda, et al. Otol Neurotol 2002;23:425-30 [10]
\end{tabular}



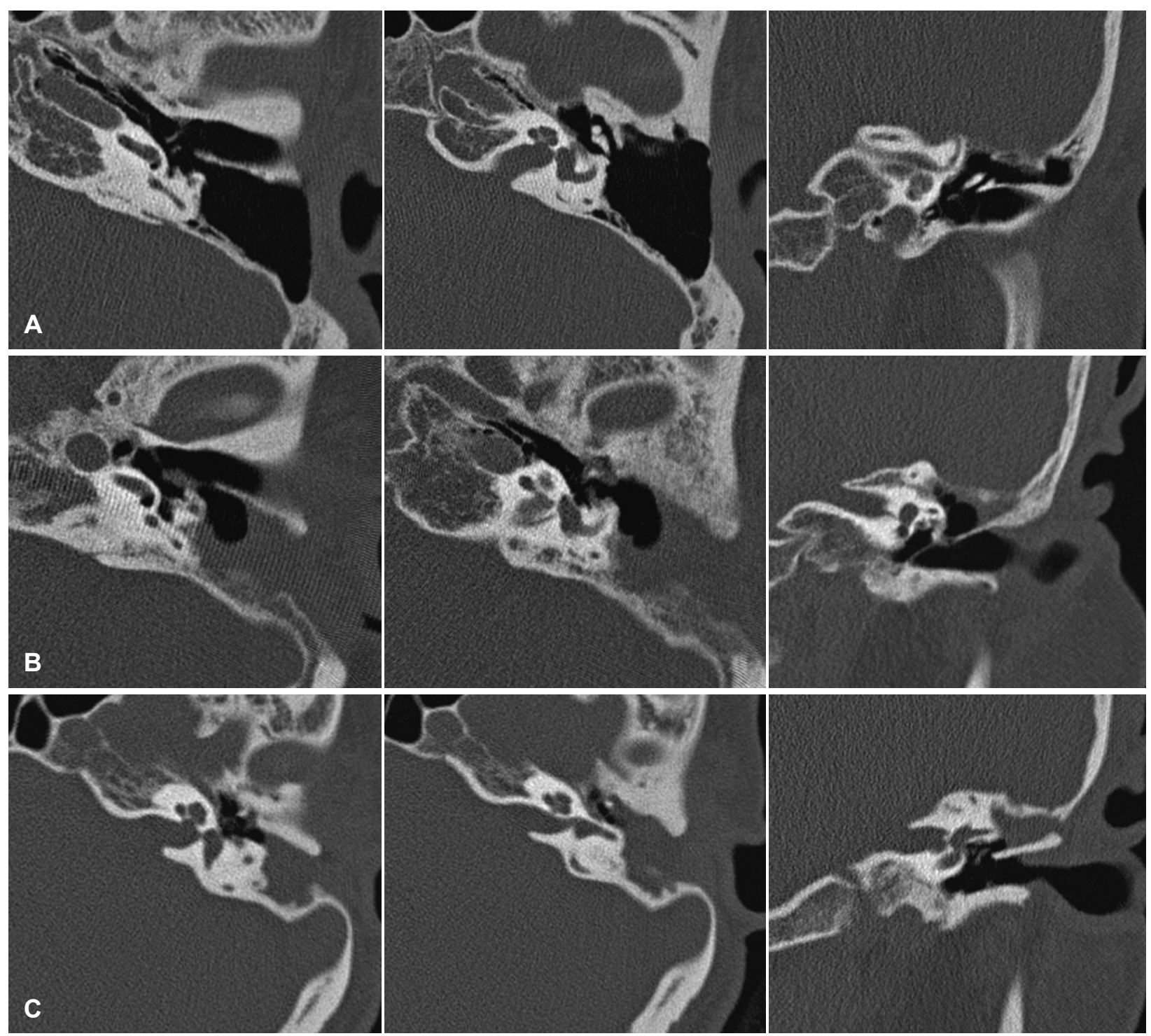

Fig. 1. Postoperative temporal bone CT images for grading mastoid aeration. The first and second columns are axial sections and the third column contains coronal sections. A: Grade I: complete mastoid aeration. B: Grade II: partial mastoid aeration. C: Grade III: absence of mastoid aeration.

tinuous variables and categorical variables were analyzed using independent 2-sample t test, chi-square test or Fisher exact test. Two-sided $p$-values of less than 0.05 were considered to be statistically significant. This study was performed in keeping with the mandate of the Declaration of Helsinki.

\section{Results}

During the study period, one surgeon (CWK) performed 493 mastoidectomies for chronic ear disease; 255 operations were for chronic suppurative otitis media, 46 were for adhesive otitis media, 138 were for attic cholesteatoma, and 54 were for pars tensa cholesteatoma. Thirty-two of the patients were under the age of 15 years old, and were therefore exclud- ed. One hundred and sixty-one canal wall down mastoidectomies were performed, so these cases were excluded. Two hundred and forty-three of the cases were followed for more than 12 months. There were 5 cases of tympanic membrane perforations and 3 cases of ventilation tube insertions performed in combination with the initial operation. Among those who had been followed up for more than 12 months, 120 cases had postoperative temporal bone CT scan images. Therefore there were 61 cases of chronic suppurative otitis media, 33 cases of adhesive otitis media, and 26 cases of attic cholesteatoma that were included in this study (Table 2). Of the included patients, 69 were females and 51 were males, with ages ranging from 16 to 73 years old (mean 45.2). Sixty-two leftsided operations and 58 right-sided operations were performed, 
and every operation was performed as a unilateral procedure.

\section{Postoperative mastoid aeration according to the preoperative diagnosis}

Grades 1 and 2 were considered to be aerated mastoid cavities; therefore, the overall mastoid aeration rate was $55.8 \%$. Postoperative mastoid aeration rate of adhesive otitis media was $21.2 \%$, while attic cholesteatoma and chronic otitis media were $53.8 \%$ and $75.4 \%$, respectively. The rates of postoperative mastoid aeration were significantly higher in the chronic otitis media cases and attic cholesteatoma cases than in the adhesive otitis media cases (Table 2).

\section{Factors affecting postoperative mastoid aeration}

The postoperative mastoid aeration was significantly associated with the preservation of the attic mucosa $(p<0.001)$. The age at operation, sex, operation side, and preservation of the middle ear mucosa were not related to the postoperative mastoid aeration (Table 3).

\section{Hearing}

The average air-bone gap was $30.5 \pm 10.6 \mathrm{~dB}$ before the operation and $18.2 \pm 12.4 \mathrm{~dB}$ after the operation. The average air-bone gap in those patients with postoperative mastoid aeration grades 1 and 2 was $16.6 \pm 10.3 \mathrm{~dB}$, and in those with grade 3 it was $24.1 \pm 9.8 \mathrm{~dB}$. Postoperatively, the average air-bone gap showed statistically significant differences between patients with postoperative aerated mastoid and airless mastoid (Table 4).

Table 2. Postoperative mastoid aeration according to the preoperative diagnosis

\begin{tabular}{|c|c|c|c|c|c|c|c|c|c|c|}
\hline & \multirow[b]{2}{*}{$\mathrm{COM}$} & \multirow[b]{2}{*}{$A C$} & \multirow[b]{2}{*}{$\mathrm{AOM}$} & \multirow[b]{2}{*}{ Total } & \multicolumn{2}{|c|}{ COM vs. AC } & \multicolumn{2}{|c|}{ COM vs. AOM } & \multicolumn{2}{|c|}{$A C$ vs. $A O M$} \\
\hline & & & & & $p$ value & $\begin{array}{l}\text { Odds ratio } \\
(95 \% \mathrm{Cl})\end{array}$ & $p$ value & $\begin{array}{l}\text { Odds ratio } \\
(95 \% \mathrm{Cl})\end{array}$ & $p$ value & $\begin{array}{l}\text { Odds ratio } \\
(95 \% \mathrm{Cl})\end{array}$ \\
\hline No. of patients & 61 & 26 & 33 & 120 & & & & & & \\
\hline Aerated mastoid cavity & & & & & 0.075 & $\begin{array}{c}2.62 \\
(1.00-6.91)\end{array}$ & $<0.001^{*}$ & $\begin{array}{c}11.39 \\
(4.11-31.52)\end{array}$ & $0.014^{*}$ & $\begin{array}{c}4.33 \\
(1.39-13.49)\end{array}$ \\
\hline Positive & 46 & 14 & 7 & 67 & & & & & & \\
\hline Negative & 15 & 12 & 26 & 53 & & & & & & \\
\hline
\end{tabular}

* $p$-value less than 0.017 was considered to indicate statistical significance (accounting for a Bonferroni correction). COM: chronic otitis media, AC: attic cholesteatoma, AOM: adhesive otitis media, $\mathrm{Cl}$ : confidence interval

Table 3. Clinical characteristics of postoperative mastoid aeration

\begin{tabular}{|c|c|c|c|c|}
\hline \multirow{2}{*}{ Characteristics } & \multirow{2}{*}{ All patients } & \multicolumn{2}{|c|}{ Aerated mastoid cavity } & \multirow{2}{*}{$p$-value } \\
\hline & & Positive & Negative & \\
\hline No. of patients & 120 & 67 & 53 & \\
\hline Age at operation* & & $45.4 \pm 14.9$ & $51.5 \pm 9.9$ & 0.135 \\
\hline$<50$ years & 64 & 40 & 24 & 0.142 \\
\hline$\geq 50$ years & 56 & 27 & 29 & \\
\hline Sex & & & & 1.000 \\
\hline Female & 69 & 38 & 31 & \\
\hline Male & 51 & 29 & 22 & \\
\hline Side & & & & 0.888 \\
\hline Left & 62 & 35 & 27 & \\
\hline Right & 58 & 32 & 26 & \\
\hline \multicolumn{5}{|l|}{ Operation findings } \\
\hline Middle ear mucosa & & & & 0.462 \\
\hline Preserved & 100 & 54 & 46 & \\
\hline Removed & 20 & 13 & 7 & \\
\hline Attic mucosa & & & & $<0.001^{\dagger}$ \\
\hline Preserved & 45 & 36 & 9 & \\
\hline Removed & 75 & 31 & 44 & \\
\hline
\end{tabular}


Table 4. Hearing results according to the postoperative mastoid aeration $(n=120)$

\begin{tabular}{lccc}
\hline & \multicolumn{2}{c}{ Aerated mastoid cavity } & \multirow{2}{*}{ p-value } \\
\cline { 2 - 3 } & Positive & Negative & \\
\hline No. of patients & 67 & 53 & \\
Preoperative PTA (dB) & $39.1 \pm 13.5$ & $40.1 \pm 14.3$ & 0.472 \\
Preoperative ABG (dB) & $28.4 \pm 11.2$ & $31.5 \pm 10.1$ & 0.286 \\
Postoperative ABG (dB) & $16.6 \pm 10.3$ & $24.1 \pm 9.8$ & $0.004^{*}$ \\
\hline
\end{tabular}

$p$-value using independent 2-sample † test. *statistically significant $(p<0.05)$. PTA: pure tone average, ABG: air-bone gap

\section{Postoperative retraction pocket of the tympanic membrane}

There were 14 cases of revision operations due to the development of retraction pocket in the tympanic membrane: 6 cases of adhesive otitis media, 6 cases of attic cholesteatoma, and 2 cases of chronic otitis media. Thirteen cases developed retraction pockets between 8 and 12 months postoperatively, and one case developed 14 months after the operation. All of the revised cases had grade 3 postoperative mastoid aeration and underwent canal wall down mastoidectomies. There were 3 cases of residual or recurrent cholesteatomas and 2 cases of newly developed cholesteatomas. The remaining 9 cases had fibrosis and granulation tissue within the mastoid cavity.

\section{Discussion}

The mastoid air cell system is believed to act primarily as a buffer to pressure changes in the middle ear cavity $[6,11,12]$. The mastoid seems to function in a way complementary to the Eustachian tube; the mastoid is related to the continuous regulation of smaller pressures, whereas the Eustachian tube is related to the intermittent regulation of higher pressures [12]. When the Eustachian tube fails to equalize pressure, negative pressure occurs in the middle ear cavity. An aerated mastoid cavity acts as a reservoir for the middle ear air system, and as a buffer to pressure changes in the middle ear cavity. When a middle ear cavity with a small mastoid develops negative pressure, this situation may lead to the development of compensatory buffering mechanisms, such as retraction or fluid accumulation, which reduced the middle ear volume [11]. Increasing or repeated negative middle ear pressure could lead to atelectasis of the tympanic membrane, formation of a retraction pocket in the attic or posterior-superior quadrant, and subsequent adhesive otitis media [13]. A well-aerated mastoid may help control significant changes in the middle ear pressure and minimize adverse effects on the middle ear and tympanic membrane. Therefore, reconstruction of the aerated mastoid cavity is one of the important goals of a mastoidectomy.

Unfortunately, re-aeration of the mastoid cavity after a ca- nal wall up mastoidectomy is not universally achieved. A soft tissue density in the postoperative mastoid cavity can represent fluid, fibrosis, or residual/recurrent cholesteatoma [7]. For example, Tierney, et al. [14] assessed the postoperative CT scans and second look surgeries after intact canal wall mastoidectomies in 43 cases. They reported soft tissue densities in the mastoid cavity in 21 cases (48.8\%), and residual or recurrent cholesteatoma in 14 cases (32.6\%). Palva [15] reported the intraoperative findings in 43 cases of revision intact canal wall mastoidectomies as follows: recurrent cholesteatoma in the mastoid cavity in $63 \%$ of the cases, and cholesterol granuloma-type changes filling the cavity in the rest. $\mathrm{He}$ concluded that the main reason for failure after the primary surgery was inadequate mastoid and epitympanic bone work, and failure to obliterate the medial parts of the cavity thoroughly. Fundamentally, a complete mastoidectomy is needed for good postoperative mastoid aeration.

It seems that the degree of postoperative mastoid aeration varies based on the preoperative middle ear disease. For instance, Takahashi, et al. [16] reported that $52 \%$ of 50 patients with chronic suppurative otitis media had mastoid re-aeration after posterior canal wall reconstruction using soft tissue, and emphasized the importance of the preservation of the epitympanic mucosa. In this study, the preservation of the attic mucosa and incudal buttress was significantly associated with postoperative mastoid aeration. However, removal of the incudal buttress was performed in those patients with extensive disease; therefore, the extent of the middle ear disease is also an important factor affecting postoperative mastoid aeration. Minoda, et al. [10] reported that $35.3 \%$ of 35 patients with cholesteatoma showed an air-filled mastoid cavity after a mastoid cortex plasty. In addition, Tono, et al. [17] reported that $20 \%$ of 5 patients with adhesive otitis media achieved postoperative mastoid aeration. In this study, we aimed to evaluate postoperative mastoid aeration according to the preoperative middle ear disease. All of the patients underwent tympanoplasties with canal wall up mastoidectomies, and a posterior tympanotomy was performed in every operation in order to create another pathway of aeration to the mastoid cavity. The overall postoperative mastoid aeration rate was $55.8 \%$, which is similar to previous reports $[7,17]$. The mastoid aeration based on the preoperative middle ear disease showed quite different results: $21.2 \%$ with adhesive otitis media, $53.8 \%$ with attic cholesteatoma, and $75.4 \%$ with chronic otitis media. The rates of postoperative mastoid aeration were significantly higher in the chronic otitis media cases and attic cholesteatoma cases than in the adhesive otitis media cases [odds ratio with chronic otitis media vs adhesive otitis media, 11.39 ; $95 \%$ confidence interval (CI), 4.11 to 31.52 ; odds ratio 
with attic cholesteatoma vs. adhesive otitis media, 4.33; 95\% CI, 1.39 to 13.49 ]. These results suggest that the tendency of the postoperative mastoid aeration is dependent on the preoperative middle ear disease.

Many chronic ear diseases are generally associated with Eustachian tube dysfunction, especially, adhesive otitis media. Therefore, we believe that the function of the Eustachian tube is another important factor for determining the degree of postoperative mastoid aeration. However, there is no method to evaluate the exact function of the Eustachian tube preoperatively. This leaves preoperative middle ear disease as the most important factor in determining postoperative mastoid aeration.

It is not certain whether an increased volume in the re-aerated mastoid can act as an enhanced buffer to pressure changes in the middle ear or not. There was no retraction pocket in the tympanic membrane when the postoperative mastoid aeration was fulfilled, whereas $26 \%$ (14 out of 53 cases) of the patients with an absence of mastoid aeration developed retraction pockets in the tympanic membrane. Therefore, when a canal wall up mastoidectomy is performed, creating a wellaerated mastoid is an important goal. In patients with adhesive otitis media, mastoid aeration was only achieved in $21.2 \%$, and $18.2 \%$ of the patients underwent revision operations due to development of retraction pockets. Those patients with adhesive otitis media require a more precise procedure to prevent retraction pockets in the tympanic membrane arising from atelectasis of the mastoid cavity.

In conclusion, postoperative mastoid aeration is associated with the type of preoperative middle ear disease. Therefore, when a surgeon plans to perform a canal wall up mastoidectomy, the middle ear disease should be considered. Furthermore, canal wall down mastoidectomy or mastoid obliteration is recommended if the patient has adhesive otitis media.

\section{Conflicts of interest}

The authors have no financial conflicts of interest.

\section{REFERENCES}

1) Brackmann DE. Tympanoplasty with mastoidectomy: canal wall up procedures. Am J Otol 1993;14:380-2.

2) Kenna MA. Treatment of chronic suppurative otitis media. Otolaryngol Clin North Am 1994;27:457-72.

3) McGrew BM, Jackson CG, Glasscock ME 3rd. Impact of mastoidectomy on simple tympanic membrane perforation repair. Laryngoscope 2004;114:506-11.

4) Ramakrishnan A, Panda NK, Mohindra S, Munjal S. Cortical mastoidectomy in surgery of tubotympanic disease. Are we overdoing it? Surgeon 2011;9:22-6.

5) Eliades SJ, Limb CJ. The role of mastoidectomy in outcomes following tympanic membrane repair: a review. Laryngoscope 2013;123: 1787-802.

6) Ruhl CM, Pensak ML. Role of aerating mastoidectomy in noncholesteatomatous chronic otitis media. Laryngoscope 1999;109:1924-7.

7) Vrabec JT, Champion SW, Johnson RF Jr, Chaljub G. Aeration following intact canal wall mastoidectomy. Ann Otol Rhinol Laryngol 2003;112(9 Pt 1):801-6.

8) Sadé J, Berco E. Atelectasis and secretory otitis media. Ann Otol Rhinol Laryngol 1976;85(2 Suppl 25 Pt 2):66-72.

9) Park MI, Kim CW, Park SM, Lee JJ, Kim HS. Usefullness of the attic reconstruction using the tragal cartilage and perichondirum for prevention of a retraction pocket. Korean J Audiol 2011;15:124-8.

10) Minoda R, Yanagihara N, Hinohira Y, Yumoto E. Efficacy of mastoid cortex plasty for middle ear aeration in intact canal wall tympanoplasty for cholesteatoma. Otol Neurotol 2002;23:425-30.

11) Cinamon U, Sadé J. Mastoid and tympanic membrane as pressure buffers: a quantitative study in a middle ear cleft model. Otol Neurotol 2003;24:839-42.

12) Gaihede M, Dirckx JJ, Jacobsen H, Aernouts J, Søvsø M, Tveterås $\mathrm{K}$. Middle ear pressure regulation--complementary active actions of the mastoid and the Eustachian tube. Otol Neurotol 2010;31:603-11.

13) Bluestone CD, Cantekin EI, Beery QC, Stool SE. Function of the Eustachian tube related to surgical management of acquired aural cholesteatoma in children. Laryngoscope 1978;88(7 Pt 1):1155-64.

14) Tierney PA, Pracy P, Blaney SP, Bowdler DA. An assessment of the value of the preoperative computed tomography scans prior to otoendoscopic 'second look' in intact canal wall mastoid surgery. Clin Otolaryngol Allied Sci 1999;24:274-6.

15) Palva T. Surgical treatment of chronic middle ear disease. III. Revisions after tympanomastoid surgery. Acta Otolaryngol 1988;105:82-9.

16) Takahashi H, Honjo I, Naito Y, Miura M, Tanabe M, Hasebe S. Cause of posterior canal wall retraction after surgery from the viewpoint of mastoid conditions. Am J Otol 1998;19:131-5.

17) Tono T, Miyanaga S, Morimitsu T, Matsumoto I. Computed tomographic evaluation of middle ear aeration following intact canal wall tympanoplasty. Auris Nasus Larynx 1987;14:123-30. 